\title{
'Ghost fishing' of target and non-target species by Norway lobster Nephrops norvegicus creels
}

\author{
J. M. Adey ${ }^{1,2}$, I. P. Smith ${ }^{2, *}$, R. J. A. Atkinson' ${ }^{2}$ I. D. Tuck ${ }^{3,4}$, A. C. Taylor ${ }^{1}$ \\ ${ }^{1}$ Institute of Biomedical and Life Sciences, Graham Kerr Building, University of Glasgow, Glasgow G12 8QQ, UK \\ ${ }^{2}$ University Marine Biological Station, Millport, Isle of Cumbrae KA28 0EG, UK \\ ${ }^{3}$ Fisheries Research Services Marine Laboratory, PO Box 101, 375 Victoria Road, Aberdeen AB11 9DB, UK \\ ${ }^{4}$ Present address: National Institute of Water and Atmosphere Research, Private Bag 109695, 269 Khyber Pass Road, \\ Newmarket, Auckland 1023, New Zealand
}

\begin{abstract}
The environmental impact of 'ghost fishing' has been identified as a major issue in the capture fishing industry. The present study assesses the potential for ghost fishing in the creel (baited trap) fishery for Norway lobster Nephrops norvegicus, one of the most valuable fished species in European waters. Baited creels were deployed and monitored at a shallow and a deep site for 363 and 217 d, respectively. Catch was counted at regular intervals by SCUBA diving at the shallow site and by periodically hauling creels at the deepwater site. Both trials showed that most captured species were able to escape from the creels, with only $N$. norvegicus being trapped for long periods of time, suggesting that creels are very selective for the target species. Dead target or non-target species within creels appeared to be ineffective at attracting additional $N$. norvegicus into the creels. It was concluded that, following the initial attraction to creels, once all the bait has been consumed, lost creels will cease to fish. The main reasons for the low ghost fishing performance of $N$. norvegicus creels may be the design of the creel itself (which allows non-target species to escape relatively easily), the behaviour of $N$. norvegicus restricting the number of animals entering the creels once the bait has been consumed, and the ability of $N$. norvegicus to survive for long periods of time once caught.
\end{abstract}

KEY WORDS: Lost fishing gear - Ghost fishing · Baited traps · Environmental impact · Gear selectivity $\cdot$ Bycatch $\cdot$ Non-target species

Resale or republication not permitted without written consent of the publishe

\section{INTRODUCTION}

'Ghost fishing' occurs when fishing gear that has been lost or abandoned continues to fish, leading to the mortality of target or non-target species (Pawson 2003), and is considered to be one of the most serious negative impacts of capture fisheries (FAO 1995, Jennings \& Kaiser 1998). It is largely confined to passive gears, such as gillnets, trammel nets and traps, which can be lost if the gear becomes snagged on the seabed or towed away by mobile fishing gear (Blyth et al. 2002), or if surface marker buoys are lost due to storms, propeller strikes (Bullimore et al. 2001, Pawson 2003), ice (Godøy et al. 2003), inadequate maintenance, theft or vandalism (Perry et al. 2003). Lost traps are a particular cause for concern as they tend to be constructed from more durable materials and have rigid, persistent structures (Parrish \& Kazama 1992, Stevens et al. 2000, Bullimore et al. 2001, Godøy et al. 2003, Perry et al. 2003, Matsuoka et al. 2005).

Little is known about the frequency of static gear loss or how long gears continue to fish. In part, this is because fishermen are reluctant to report such incidents and also because ghost fishing studies are necessarily long term (Pawson 2003). Estimates of the loss of traps vary greatly among studies, which is to be expected when comparing different fisheries. A fishery on a rocky substratum is likely to have greater loss 
than one on a soft substratum, owing to the increased likelihood of snagging and storm damage. On the other hand, lost traps may remain intact for longer on a soft substratum. The problem of estimating gear loss is highlighted by 2 separate studies on the North American Bristol Bay king crab Paralithodes camtschaticus fishery, which estimated the annual loss of traps to be 31600 and 7000, respectively (Kruse \& Kimker 1993, Paul et al. 1994, Stevens 1996). Furthermore, few studies have quantified the length of time lost traps continue to fish. The degree of biofouling has been used to gauge the age of lost nets, but rates of biofouling are very dependent on local environmental conditions (Saldanha et al. 2003). The duration of ghost fishing by lost traps is, however, likely to be considerable on account of their durability. For example, Bullimore et al. (2001) found that parlour pots designed for the crab Cancer pagurus and lobster Homarus gammarus continued to attract crustaceans and fish for more than 1 yr.

Once lost, baited traps can cause mortality for a number of reasons. Animals may starve to death if they cannot escape or may be killed by predators or conspecifics that have also entered the trap and which may also subsequently become trapped themselves. Furthermore, the gear may continue to fish after the bait has been exhausted, since animals that die in the traps may effectively re-bait them, leading to a continuous cycle of capture, decay and attraction for as long as the gear remains intact (Bullimore et al. 2001).

The level of mortality from ghost fishing appears to vary considerably among trap fisheries. In a Dungeness crab Cancer magister fishery, Breen (1987) showed that lost traps could continue to fish for $12 \mathrm{mo}$ and estimated that the ghost fishing catch amounted to ca. $7 \%$ of annual landings. High levels of mortality from ghost fishing have also been found in studies of other decapod fisheries (Kimker 1994, Bullimore et al. 2001, Hébert et al. 2001). In contrast, studies of king crabs Paralithodes camtschatica (High \& Worlund 1979, Godøy et al. 2003), slipper and spiny lobsters Scyllarides squammosus and Panulirus marginatus (Parrish \& Kazama 1992) and American lobsters Homarus americanus (Jury et al. 2001) have indicated that most individuals that enter lost traps are eventually able to escape. The impact of ghost fishing will therefore vary among species and gear designs.

Most studies of ghost fishing in crustacean trap fisheries have focused on the effect on target populations. Stevens et al. (2000) recorded a range of taxa caught in lost Tanner crab Chionoecetes bairdi traps in Alaska, although the target species was the most abundant. Bullimore et al. (2001) found that parlour pots designed for the crab Cancer pagurus and lobster Homarus gammarus caused mortality of not only the target spe- cies, but also other crustacean and fish species when left on the seabed for long periods.

The Norway lobster Nephrops norvegicus is the most important commercial crustacean in European seas (Bell et al. 2006). Most of the landings are taken by trawling, but in some areas, fishing with baited traps (or 'creels') accounts for a significant proportion, particularly in terms of monetary value (Bell et al. 2006). Trawling for $N$. norvegicus has a significant impact on benthic communities (Tuck et al. 1998, Queiros et al. 2006, Tillin et al. 2006) and can take a substantial bycatch of non-target species (Bergmann et al. 2002, Catchpole et al. 2005). Although creeling is expected to have less physical impact on the seabed (Eno et al. 2001), it may have adverse environmental effects through ghost fishing (Jennings \& Kaiser 1998).

There have been no previous attempts to quantify the effects of ghost fishing on Nephrops norvegicus populations, yet it has been highlighted as a key issue in certain areas (Wester Ross Biodiversity Group 2004, Zeigler 2006). Swarbrick \& Arkley (2002) found that the majority of $N$. norvegicus creel losses were caused by trawls and scallop dredges being towed through fleets of creels. There was no mention of losses due to snagging on the seabed, which is less common on the seabeds typical of $N$. norvegicus creel fishing grounds. Swarbrick \& Arkley (2002) also observed that it was common practice for creel fishermen to use only half of their gear and to store the rest in deepwater, unbaited until required again. This is a cause for concern in relation to ghost fishing. It was reported that some fishermen left the creel doors open to prevent ghost fishing, but this practice was not universal.

There is a need to quantify the potential impacts of ghost fishing in Nephrops norvegicus creel fisheries. The objectives of the present study were to investigate the capture and retention over time of both target and non-target species in lost creels set for $N$. norvegicus, to quantify the resulting mortality and to assess the effect of escape gaps on the retention of selected species.

\section{MATERIALS AND METHODS}

Ghost fishing trials were conducted using typical Nephrops norvegicus creels (CF00089, Gael Force Marine) consisting of a plastic-coated steel frame (Dshape in cross section, $8 \mathrm{~mm}$ rod) measuring $55 \times 42 \times$ $32 \mathrm{~cm}$, covered with $30 \mathrm{~mm}$ mesh polyethylene netting, with a horizontal funnel entrance on each side, each leading to a $75 \mathrm{~mm}$ diameter 'hard' eye (a polypropylene ring), and a hinged door at one end fastened by a hook on a rubber strip. Bait was held in the centre of the creel between 2 taught vertical lengths of twine. As supplied, the netting covering most of the creel was 
green; it was bound to the frame with orange twine and the funnels were of white nylon netting. Some creels were modified to create rounded oblong 'escape gaps' (aperture $97 \times 23 \mathrm{~mm}$ ) low on the creel door, which were designed to allow smaller $N$. norvegicus (<40 mm carapace length, CL) to pass through. Escape gaps were formed by clipping 2 plastic frames together on either side of the creel door and cutting away the enclosed netting ('Escape hatches', Stornoway Plastics: note that, despite the proprietory name, no hatch mechanism was involved).

Two ghost fishing trials were conducted: at a shallow site, where divers could monitor creels in situ, and at a deeper site, more typical of commercially fished Nephrops norvegicus grounds. The first trial was on a shallow N. norvegicus ground in Sailean Mhór, an arm of upper Loch Sween, Argyll. This is a relatively shallow, sheltered sea loch where there is both trawling and creeling for $N$. norvegicus, but fishing in Sailean Mhór is primarily by creeling. Four fleets of 5 standard $N$. norvegicus creels, each baited with salted herring or mackerel, were deployed from a small boat onto a muddy seabed with $N$. norvegicus burrows at a depth of 16 to $18 \mathrm{~m}$ below chart datum $\left(56^{\circ} 2.1^{\prime} \mathrm{N}, 5^{\circ} 34.5^{\prime} \mathrm{W}\right)$ on 10 November 2004. Fleets were positioned parallel to the shore, with each fleet being several metres apart. Creels fitted with escape gaps were alternated with those without gaps. Creels were individually labelled so that their contents could be recorded separately on each sampling occasion. Creels were examined by SCUBA divers 1, 2, 5, 6, 7, 8, 9 and $23 \mathrm{~d}$ after deployment and approximately monthly thereafter until Day 363. Numbers and species of captured animals were recorded. The presence of dead animals was recorded, ensuring that body parts were distinguished from moulted exoskeletons. The size and sex of captured $N$. norvegicus were noted, making it possible to distinguish individual animals between consecutive sampling occasions. Size was estimated by eye, because removing animals for measurement would have disrupted the experiment. On the final sampling day, in addition to examination in situ, the creels were lifted, and the same details were recorded at the surface.

The second trial was held in Loch Torridon, Wester Ross, a deep sea loch where trawling is not permitted and fishing for Nephrops norvegicus is by creeling only. A fleet of 27 individually labelled $N$. norvegicus creels, 16 with escape gaps (randomly arranged) and 11 without (all baited with salted herring), was deployed from a commercial fishing vessel in the outer basin of Loch Torridon, close to the mouth of Loch Beag $\left(57^{\circ} 32.97^{\prime} \mathrm{N}, 5^{\circ} 43.16^{\prime} \mathrm{W}\right)$, at a water depth of $60 \mathrm{~m}$, on 19 April 2005. The creels were examined 22, $37,62,88,123,168$ and 217 d after deployment (observations were less frequent and regular than in the Loch
Sween trial, owing to adverse weather conditions and logistical constraints). On each sampling occasion, the creels were hauled to the surface for inspection on board the vessel and the number of each species captured in each creel was recorded. For reasons of practicality (needing to work at commercial fishing speed, with not always the same recorder), $N$. norvegicus size was recorded as 'small' (36 to $44 \mathrm{~mm} \mathrm{CL}$ ), 'medium' (45 to $48 \mathrm{~mm} \mathrm{CL}$ ) or 'large' (>48 mm CL) and sex was noted. Because the creels were hauled from depth, any fish with a swim bladder was unlikely to survive, owing to the rapid change in pressure. Such fish were removed from the creels so they would not bias the results (i.e. by acting as bait). It was assumed that this removal procedure had little effect on the findings, since the Loch Sween experiment had already shown that fish were able to escape from the creels. Once the catch was recorded, the creels were returned to the same location from which they were hauled.

The Nephrops norvegicus catch data have been expressed as catch-per-unit-effort (CPUE) using the following formula (Bullimore et al. 2001):

$$
\mathrm{CPUE}=\frac{N_{\text {curr }}}{E\left(t_{\text {curr }}-t_{\text {prev }}\right)}
$$

where $N_{\text {curr }}$ is the number of newly caught animals in the current sample, $E$ is the number of creels fishing, and $t_{\text {curr }}-t_{\text {prev }}$ is the time interval in days since the previous sample.

The numbers of selected species caught per creel were compared between creels with escape gaps and those without using Kruskal-Wallis tests (the prevalence of 0 counts in individual creels precluded ANOVA). The catch in each creel over the study period was expressed in 2 ways: as the maximum number of individuals present at any time and as the average number present. Additionally, in the Loch Sween experiment, these metrics were tested over the period when the bait was exhausted (Days 64 to 363).

The length of time that individual Nephrops norvegicus remained captured (residence time) was estimated for the Loch Sween creel deployment. Differences in residence time among $N$. norvegicus size categories were tested with 1-way ANOVA. The relationship between the date on which an individual $N$. norvegicus entered the creel and residence time was tested with regression analysis.

\section{RESULTS}

\section{Loch Sween}

Bait in the creels was consumed rapidly; only 7 of the 20 creels had remnants of bait by Day 9 (Fig. 1). 


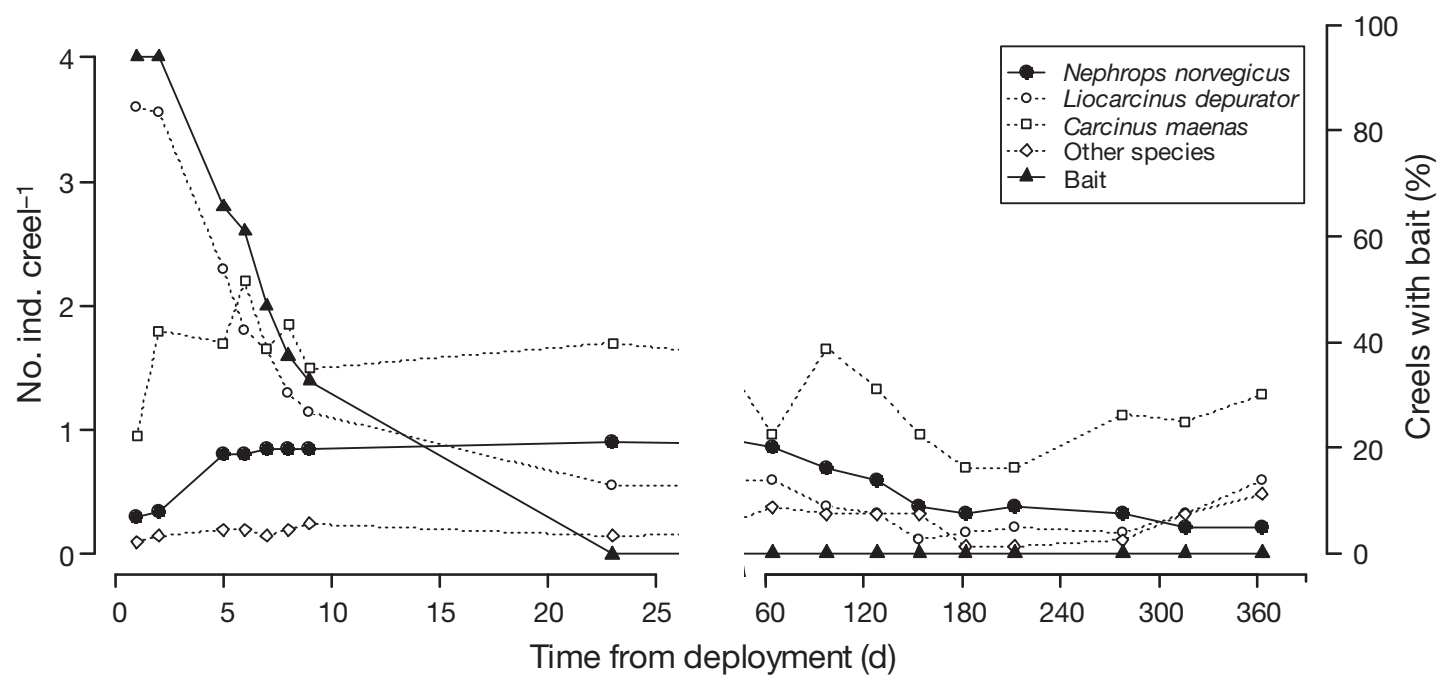

Fig. 1. Number of individuals per creel by species in Loch Sween as a function of time since deployment. The percentage of creels with bait remaining is also indicated. Other species: total catch of Cancer pagurus, Asterias rubens, Crossaster papposus, Aequipecten opercularis, Trisopterus minutus, Scyliorhinus canicula and Gadus morhua

Throughout the experiment most of the creels were left undisturbed until Day 299, when 5 were found to have been moved ca. $30 \mathrm{~m}$ from their original position, although they remained at a similar depth and on the same type of seabed as initially. These creels were not discounted as, from discussion with commercial fishermen, it is known that under normal conditions lost creels may often be moved by other fishing gear.

In total, 10 different species were observed, with only Nephrops norvegicus and the crabs Liocarcinus depurator and Carcinus maenas being recorded in large numbers. L. depurator appeared in large numbers in the creels on the first day; there was a rapid decline over the following $9 \mathrm{~d}$, then a slow decline until the bait was exhausted, after which numbers fluctuated at fewer than 10 individuals in total. Numbers of C. maenas increased more gradually to a peak on Day 6, after which there was a slow decline. Beyond Day 23, the numbers of C. maenas fluctuated without obvious trend. $N$. norvegicus was third in abundance. The total number of $N$. norvegicus increased until Day 7, remained relatively stable until Day 60, then gradually declined (Fig. 1). Fish, including Gadus morhua, Trisopterus minutus (which may have included some T. esmarkii) and Scyliorhinus canicula, were caught in small numbers and their pattern of occurrence suggested that they were able to enter and leave creels. After $3 \mathrm{wk}$, when the bait was exhausted, few specimens of non-target bycatch were present in the creels (Fig. 1).

There were 2 recorded mortalities of Nephrops norvegicus during the trial (on Days 64 and 212), out of a total of 27 lobsters entering traps (7\%; $95 \%$ confidence interval: 0.9 to $24.3 \%$; Zar 1999). Deaths of some crab species occurred between Days 97 and 154 (12 Carcinus maenas, 5 Liocarcinus depurator, 1 Cancer pagurus), leading to a short-term small increase in the number of scavengers, including the starfish Asterias rubens and C. pagurus. No entries by $N$. norvegicus to the creels were recorded during the period when crab deaths were observed.

Slight increases in a number of species were observed at the end of the experiment (Fig. 1), coinciding with a large settlement of the tubicolous polychaetes Sabella pavonina on the creels. Inspection of the creels at the surface at the end of the experiment revealed that $28 \%$ of Carcinus maenas and $16 \%$ of Liocarcinus depurator had not been counted in the final in situ inspection. This was due to the dense

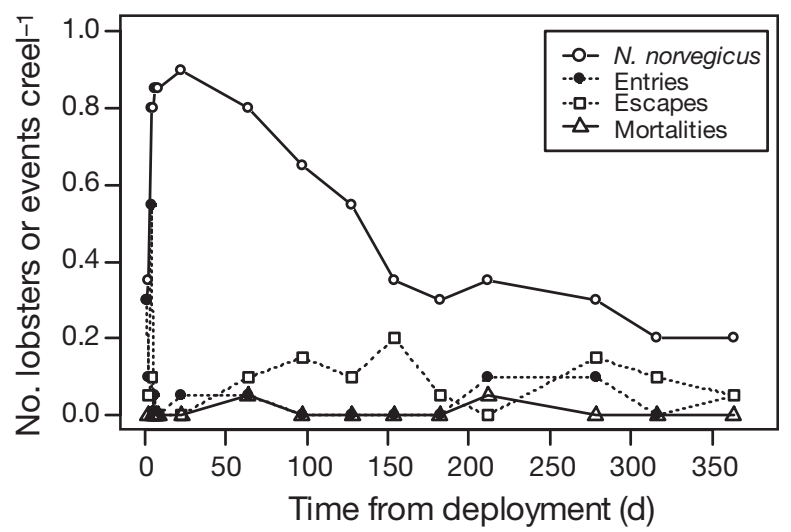

Fig. 2. Nephrops norvegicus. Entries, escapes and mortalities per creel in Loch Sween as a function of time since deployment. The number of live individuals remaining per creel is also shown 




Fig. 3. Nephrops norvegicus. Catch per unit effort (CPUE) of creels in relation to time since deployment in Loch Sween

growths of $S$. pavonina obscuring the interior of the creels from the view of divers. It must therefore be assumed that on the last 2 sampling occasions, the number of animals observed within the creels was slightly underestimated, but prior to this visibility was good.

The majority of entries to the creels by Nephrops norvegicus occurred during the first few days, when bait was still present. Following this, the number of entries remained very low, with none observed between Days 182 and 316 (Fig. 2). The higher catch rates when the bait was present are clearly illustrated when the catch is expressed as CPUE (Fig. 3). A low escape rate from creels was observed, with the greatest number of escapes occurring when bait was still present (Fig. 2).

The relatively high numbers of Nephrops norvegicus caught initially, followed by low escape rate and low mortality levels, resulted in an average residence time for a single $N$. norvegicus of $111.7 \mathrm{~d}$. There was no significant effect of size $\left(F_{2,22}=2.16, \mathrm{p}=0.14\right)$ or presence of escape gaps on residence time $\left(F_{1,23}=0.82, \mathrm{p}=0.375\right)$, nor was there a significant relationship between residence time and date of entry $\left(F_{1,23}=0.00, \mathrm{p}=0.968\right)$.

Nephrops norvegicus observed in the creels were predominantly 'large' (>48 mm CL) and medium-sized (45 to $48 \mathrm{~mm} \mathrm{CL}$ ) lobsters (52 and 44\%, respectively), with few 'small' (36 to $44 \mathrm{~mm} \mathrm{CL}$ ) individuals (4\%). Most captured individuals (78\%) were eventually able to escape, in some cases after long periods of captivity.
The only species to differ significantly in numbers per creel in relation to the presence or absence of an escape gap was the small swimming crab Liocarcinus depurator. The maximum number of individuals per creel was higher in creels without an escape gap than in those with an escape gap (Table 1, Kruskal-Wallis $H=8.87, \mathrm{p}=0.003$ ). The average number of $L$. depurator per creel differed in the same way (Table $1, H=$ 14.29, $\mathrm{p}<0.001)$. During the period when no bait remained in the creels (Days 64 to 363) and the overall numbers of $L$. depurator had declined (Fig. 1), the difference between creel types was less marked, for both the maximum number of individuals (Table $1, H=2.34$, $\mathrm{p}=0.126)$ and the average number of individuals per creel (Table 2, $H=4.51, \mathrm{p}=0.034$ ).

\section{Loch Torridon}

Remnants of bait in the creels were present on Day 22, but no traces were found by Day 37. Throughout the experiment, 14 different species were caught, with Nephrops norvegicus being the most abundant. The majority of individuals in the creels on Day 22 were $N$. norvegicus, suggesting that during the first few weeks, large numbers of this lobster were caught. This was followed by a marked decline in numbers until Day 123, after which time numbers remained low (Fig. 4). During the period when the numbers of $N$. norvegicus declined, the numbers of Porania pulvillus,

Table 1. Maximum and average number of individuals per creel with $(n=10)$ and without $(\mathrm{n}=10)$ an escape gap (mean $\left.\pm \mathrm{SD} \mathrm{creel}^{-1}\right)$ by taxon, in 2 time periods of the Loch Sween trial. Also shown is the significance of Kruskal-Wallis tests comparing the 2 types of creel $\left({ }^{*} \mathrm{p}<0.05,{ }^{* *} \mathrm{p}<0.01,{ }^{* * *} \mathrm{p}<0.001\right)$

\begin{tabular}{|lcccc|}
\hline \multirow{2}{*}{ Taxon } & \multicolumn{2}{c}{ Period 1 to $363 \mathrm{~d}$} & \multicolumn{2}{c|}{ Period 64 to $363 \mathrm{~d}$} \\
& Gap & No gap & Gap & No gap \\
\hline $\begin{array}{l}\text { Maximum } \\
\text { Nephrops } \\
\text { norvegicus }\end{array}$ & $1.03 \pm 1.059$ & $1.27 \pm 0.783$ & $0.90 \pm 1.101$ & $0.90 \pm 0.738$ \\
$\begin{array}{l}\text { Liocarcinus } \\
\text { depurator }\end{array}$ & $3.67 \pm 0.981$ & $6.83 \pm 2.593^{* *}$ & $0.90 \pm 1.101$ & $1.60 \pm 0.966$ \\
$\begin{array}{l}\text { Carcinus maenas } \\
\text { Other decapods }\end{array}$ & $0.50 \pm 1.054$ & $3.40 \pm 1.174$ & $2.40 \pm 0.966$ & $2.90 \pm 0.994$ \\
$\begin{array}{l}\text { Asteroidea } \\
\text { Pisces }\end{array}$ & $0.50 \pm 0.527$ & $0.80 \pm 1.033$ & $0.40 \pm 0.516$ & $0.80 \pm 1.033$ \\
$\begin{array}{l}\text { Average } \\
\text { Nephrops }\end{array}$ & $0.53 \pm 0.571$ & $0.43 \pm 0.568$ & $0.10 \pm 0.316$ & $0.30 \pm 0.483$ \\
$\quad$ norvegicus & $0.67 \pm 0.787$ & $0.44 \pm 0.414$ & $0.56 \pm 0.681$ & $0.27 \pm 0.311$ \\
Liocarcinus & $0.52 \pm 0.164$ & $1.66 \pm 0.521^{* * *}$ & $0.13 \pm 0.172$ & $0.46 \pm 0.379 *$ \\
$\quad$ depurator & & & & \\
Carcinus maenas & $1.18 \pm 0.513$ & $1.48 \pm 0.620$ & $0.84 \pm 0.410$ & $1.22 \pm 0.409$ \\
$\begin{array}{l}\text { Other decapods } \\
\text { Asteroidea }\end{array}$ & $0.05 \pm 0.094$ & $0.12 \pm 0.122$ & $0.03 \pm 0.075$ & $0.18 \pm 0.235$ \\
Pisces & $0.04 \pm 0.041$ & $0.09 \pm 0.118$ & $0.06 \pm 0.079$ & $0.16 \pm 0.190$ \\
& $0.07 \pm 0.077$ & $0.03 \pm 0.033$ & $0.01 \pm 0.035$ & $0.03 \pm 0.054$ \\
\hline
\end{tabular}




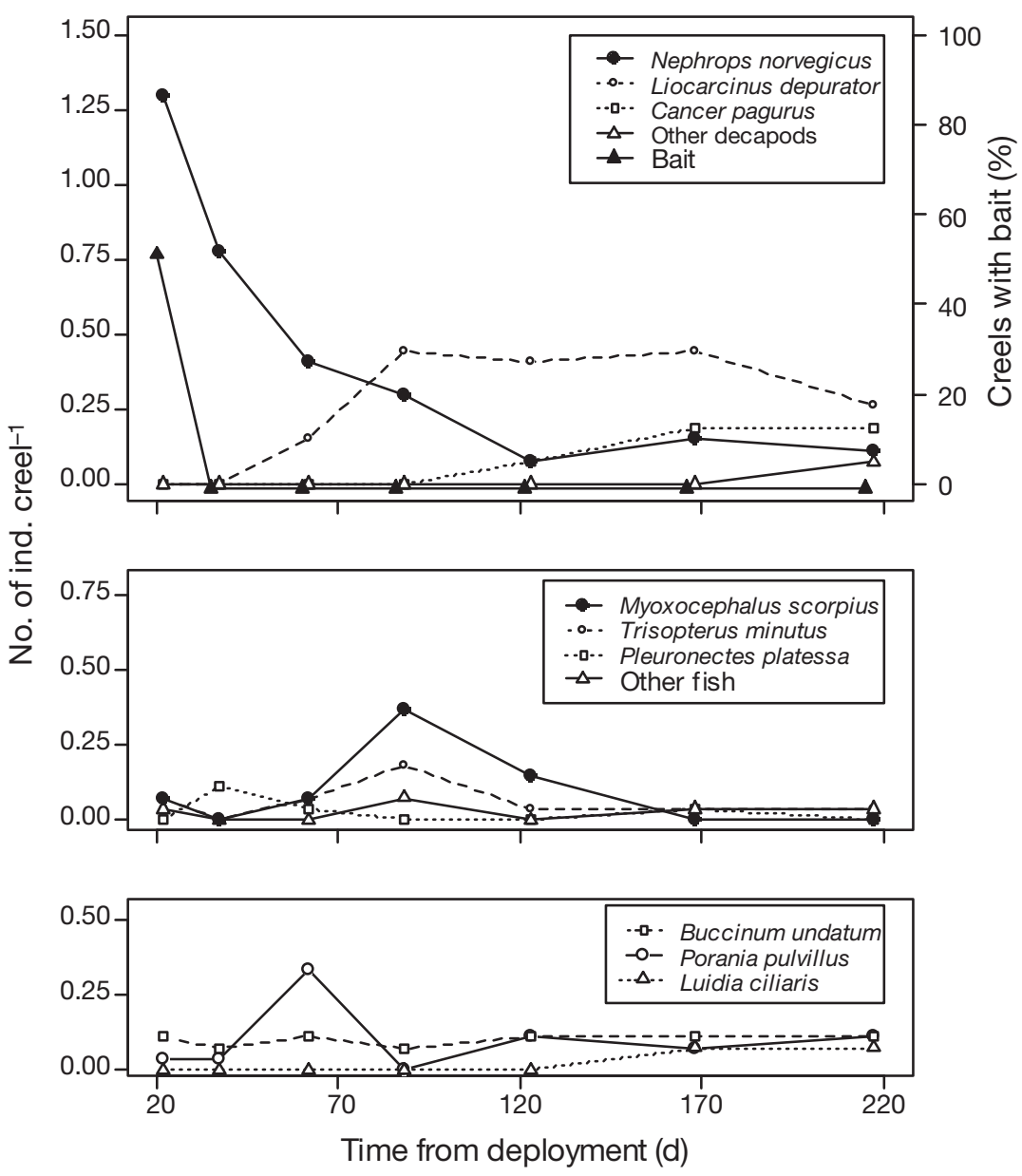

Fig. 4. Number of individuals per creel by species in Loch Torridon as a function of time since deployment. 'Other decapods' comprises Munida rugosa and Necora puber; 'Other fish' comprises Zeus faber, Phrynorhombus sp. and Labrus mixtus. The percentage of creels with bait remaining is also indicated
Liocarcinus depurator, Myoxocephalus scorpius and Trisopterus minutus (which may have included some T. esmarkii) increased. The increase in $P$. pulvillus, M. scorpius and T. minutus was followed by a subsequent decrease in numbers. By Day 168, all 3 species either were recorded in very low numbers or were not present in the creels (Fig. 4). Following the increase in L. depurator, the number of that species remained high for the rest of the experiment. All other species were recorded in small numbers at different times during the deployment (Fig. 4), and no mortalities of any species were observed.

The time course of entries and exits by Nephrops norvegicus was more difficult to assess in the Loch Torridon study because of the generalized size recording of individuals and the longer time periods between sampling. However, the data suggest that the majority of creel entries occurred when the bait was still present (Fig. 5). Catch rates were higher when bait was present (Fig. 6). Similarly, the decrease in entries of $N$. norvegicus to creels was accompanied by a decrease in the number of escapes, following which escapes remained low (Fig. 5). No dead $N$. norvegicus (either whole or fragments) were observed, suggesting that the majority were able to escape (94\%). The relative abundance of the 3 size categories of observed $N$. norvegicus was: 'small' $68 \%$, 'medium' $31 \%$ and 'large' $1 \%$.

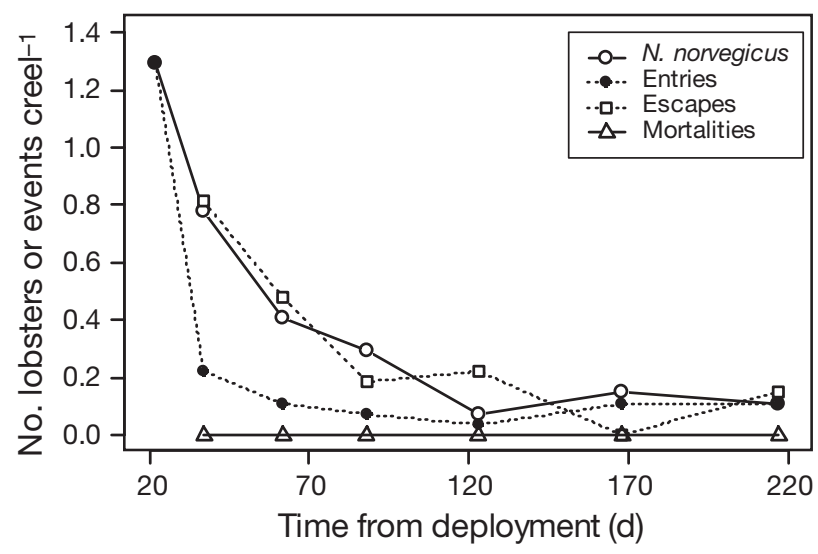

Fig. 5. Nephrops norvegicus. Entries, escapes and mortalities per creel in Loch Torridon in relation to time since deployment. The number of live individuals remaining per creel is also shown

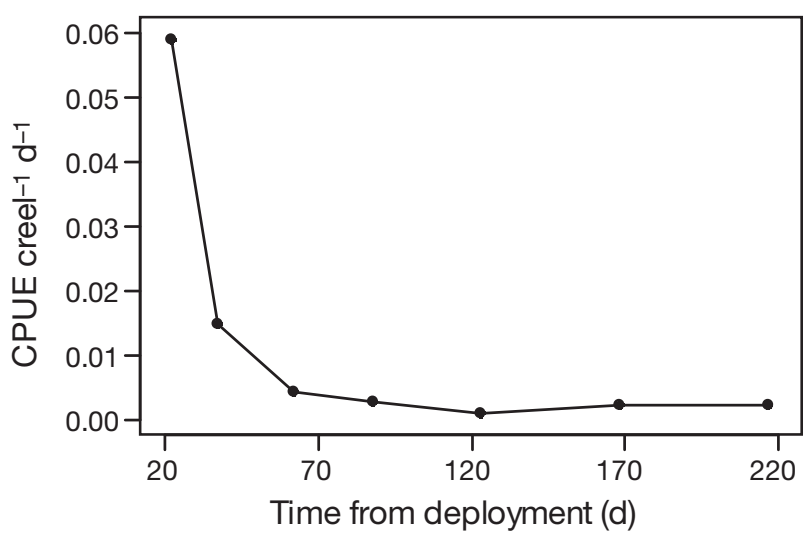

Fig. 6. Nephrops norvegicus. Catch per unit effort (CPUE) of creels in relation to time since deployment in Loch Torridon 
There were no significant differences between creels with escape gaps and those without in the maximum number of individuals per creel for any species ( $p>0.05)$. As in the Loch Sween trial, the number of Liocarcinus depurator per creel (averaged over the study period for each creel) was higher in creels without escape gaps (mean $\pm \mathrm{SD}, 0.36 \pm 0.281 \mathrm{creel}^{-1}, \mathrm{n}=$ 11) than in those with escape gaps $\left(0.16 \pm 0.187 \mathrm{creel}^{-1}\right.$, $\mathrm{n}=16 ; H=5.01, \mathrm{p}=0.025$ ).

\section{DISCUSSION}

A number of different species were observed in the ghost fishing creels in both trials, with variations in the species composition between sites reflecting different environments in which the creels were located. All species were evidently able to escape from the creels following capture, although there was an apparent difference in a species' ability to escape, reflected in the time periods spent within the creel. The ability of animals to escape is likely to be due to the simple design of the single-compartment creels, as well as the 'hard' eyes (polypropylene rings forming the apertures of the inner ends of the entrance funnels) providing a more accessible exit than is found in creels with more complicated designs or those with 'soft' eyes (no eye ring).

Nephrops norvegicus was the only species observed to stay in the creels for long periods of time. This indicates that $N$. norvegicus creels are highly selective for their target species. $N$. norvegicus appeared to be able to escape more easily in the Loch Torridon deployment than in Loch Sween. This may reflect the size of specimens caught at each location, as it seems likely that smaller individuals, such as those recorded in the Loch Torridon deployment, would be able to escape more easily (Livingstone 2001, Adey 2007). In Loch Sween, nearly all of the trapped lobsters were too large to pass through the escape gap (Livingstone 2001) and escapees must have exited through one of the eyes. The difference in $N$. norvegicus size between trials may be a reflection of the time of year the trials commenced and environmental conditions, since the size distribution of creel-caught $N$. norvegicus varies seasonally and spatially (Adey 2007).

Results from both trials suggest that mortality of Nephrops norvegicus trapped in lost creels is low, with only 2 observed mortalities in the Loch Sween experiment and none in the Loch Torridon study. However, it should be noted that, in the Loch Sween study, the estimated percentage of creel entries resulting in death has wide confidence limits. Nevertheless, it appears that $N$. norvegicus can survive for long periods within creels and the majority are eventually able to escape. The fact that there were no observed mortalities in
Loch Torridon may be a reflection of their smaller size, which allows them to escape more readily. The 2 mortalities of $N$. norvegicus in the Loch Sween experiment coincided with entries by additional $N$. norvegicus. These entries were not to the creels in which the dead animals were found, so, in contrast to a previous study by Bullimore et al. (2001), there is no direct evidence that these mortalities attracted new $N$. norvegicus into the creels. It has been suggested that some dead or damaged crustaceans may release chemicals eliciting an avoidance reaction in others of the same species (Hancock 1974). Avoidance of creels containing dead conspecifics has been observed in Cancer pagurus (Chapman \& Smith 1979) and N. norvegicus (Chapman 1981).

Several uncertainties must be considered when estimating mortality rates. In particular, dead Nephrops norvegicus may be consumed by predators or, once dead, be eaten by other animals within the creel. This may have occurred in the case of Loch Torridon, as there were often long time periods between observations and body parts may have been lost from the creels during hauling to the surface. In the Loch Sween trial, this uncertainty is much lower, as the creels were observed in situ, enabling body parts to be used to indicate the number of dead individuals. Furthermore, individual animals inhabited creels for long time periods, confirming that mortality due to starvation or predation was very low.

Mortality can be overestimated if the number of individuals that have entered and left the creels between observations is high, since mortality is estimated from the number of live and dead individuals in the creel when the observations take place (Godøy et al. 2003). The Loch Sween trial showed that individual animals were resident in the creels for long time periods, suggesting that this error is likely to be low.

Some mortalities of the crabs Carcinus maenas, Liocarcinus depurator and Cancer pagurus were observed in the Loch Sween experiment, with the majority found between February and April (3 to 5 mo after deployment). It is likely that mortalities occurred due to crabs moulting in the creel, making them vulnerable to other animals. Discussions with a number of fishermen have suggested that some crabs, particularly $L$. depurator, are good bait for Nephrops norvegicus. However, during this time of high crab mortality, no new $N$. norvegicus were observed in the creels, suggesting that these crabs did not act as bait for $N$. norvegicus during the present trial.

In general, in both trials, there were similar time courses of abundance of different species in the creels. The initial 2 phases of ghost fishing described by Miller (1990) were clearly shown in the Loch Sween deployment: a short phase of high catch rates when the 
bait is an attractant, followed by a long phase of low catch rates as the effectiveness of the bait diminishes. The first phase was not apparent in the Loch Torridon deployment because the creels were first sampled after $22 \mathrm{~d}$.

The particular phenomenon that raises concern about ghost fishing is 're-baiting' by individuals that have died within the creel (Bullimore et al. 2001, Matsuoka et al. 2005). Although there was some mortality of individuals in the Loch Sween experiment, this was followed by only small increases in numbers of a few non-target species. There is therefore little evidence from the present work to suggest that once lost, Nephrops norvegicus creels continue to fish by self rebaiting.

Another phase was observed in the Loch Sween experiment. Towards the end of the creel deployment, an increase in the number of Carcinus maenas, Liocarcinus depurator, Asterias rubens and Crossaster papposus was observed, coinciding with dense aggregations of the sabellid polychaete Sabella pavonina on the creels. Matsuoka et al. (2005) noted that the ghost fishing effectiveness of creels reduces with the accumulation of fouling organisms. It is possible that these animals observed within the creels at the end of the experiment were not actually trapped, but may have been using the creels as a shelter providing protection from predation. An analogous increase was not observed in the Loch Torridon experiment; however, on Day 217, when the creels were finally lifted, several of the creels had a number of tunicates attached to them. It is possible that if these creels were left for much longer, a similar result may have been found to that observed in Loch Sween.

Both of the present trials indicated that creels with escape gaps held fewer individuals of the swimming crab Liocarcinus depurator than those without. The small body size, dorsoventrally flattened morphology and mode of locomotion of $L$. depurator would enable it to pass through the escape gap relatively easily. Other species, including Nephrops norvegicus in the size range observed, were too large to pass through the escape gap and there was therefore no difference between the 2 creel types in the mean number of $N$. norvegicus trapped. Observational studies have shown that $N$. norvegicus are deterred from entering creels containing L. depurator (Adey 2007). It is therefore possible that by reducing the number of $L$. depurator present, escape gaps would tend to increase the number of $N$. norvegicus captured in ghost fishing creels, but the present findings did not substantiate this.

The present findings suggest that, in contrast to the conclusions of several previous studies of trap fisheries (Pecci et al. 1978, Breen 1987, Kimker 1994, Bullimore et al. 2001, Hébert et al. 2001), ghost fishing is unlikely to be a problem in the Nephrops norvegicus creel fishery, as long as lost creels remain on $N$. norvegicus grounds. It appears that, after the initial capture period when bait is still present, the majority of non-target species will be able to escape in a relatively short space of time. Those $N$. norvegicus that have been caught may remain in the creel for long periods, but are likely to escape eventually, with only a small percentage dying as a result of being caught. In addition, mortalities of target or non-target species seem to be relatively ineffective in attracting $N$. norvegicus into the creels. The main reasons for the low ghost fishing effectiveness of $N$. norvegicus creels appear to be that the design of the creel itself ('hard' eyes and escape gap) allows non-target species to escape relatively easily, the behaviour of $N$. norvegicus restricts the number of conspecifics entering the creel once the bait has been consumed (Adey 2007) and N. norvegicus is able to survive for long periods of time once caught, which increases the chances of eventual escape.

Acknowledgements. This study was funded by the Natural Environment Research Council (NER/S/A/2003/11240), Fisheries Research Services, Scottish Natural Heritage and The Highland Council. We are grateful to Shieldaig Export and D. Livingstone for facilitating the fieldwork, to N. A. Kamenos and K. S. Cameron for diving support and to J. Kennett for site access.

\section{LITERATURE CITED}

Adey JM (2007) Aspects of the sustainability of creel fishing for Norway lobster, Nephrops norvegicus (L.), on the west coast of Scotland. PhD thesis, University of Glasgow

Bell MC, Redant F, Tuck I (2006) Nephrops species. In: Phillips BF (ed) Lobsters: biology, management, aquaculture and fisheries. Blackwell Publishing, Oxford, p 412-461

Bergmann M, Wieczorek SK, Moore PG, Atkinson RJA (2002) Discard composition of the Nephrops fishery in the Clyde Sea area, Scotland. Fish Res 57:169-183

> Blyth RE, Kaiser MJ, Edwards-Jones G, Hart PJB (2002) Voluntary management in an inshore fishery has conservation benefits. Environ Conserv 29:493-508

Breen PA (1987) Mortality of Dungeness crabs caused by lost traps in the Fraser River Estuary, British Columbia. N Am J Fish Manag 7:429-435

Bullimore BA, Newman PB, Kaiser MJ, Gilbert SE, Lock KM (2001) A study of catches in a fleet of 'ghost-fishing' pots. Fish Bull (Wash DC) 99:247-253

Catchpole TL, Frid CLJ, Gray TS (2005) Discarding in the English north-east coast Nephrops norvegicus fishery: the role of social and environmental factors. Fish Res 72:45-54

Chapman CJ (1981) Discarding and tailing Nephrops at sea. Scott Fish Bull 46:10-13

Chapman CJ, Smith GL (1979) Creel catches of crab, Cancer pagurus L. using different baits. J Cons Int Explor Mer 38: 226-229

Eno NC, MacDonald DS, Kinnear JAM, Amos SC and others (2001) Effects of crustacean traps on benthic fauna. ICES J Mar Sci 58:11-20 
FAO (Food and Agriculture Organization of the United Nations) (1995) Code of conduct for responsible fisheries. FAO, Rome

Godøy H, Furevik DM, Stiansen S (2003) Unaccounted mortality of red king crab (Paralithodes camtschaticus) in deliberately lost pots off Northern Norway. Fish Res 64: 171-177

Hancock DA (1974) Attraction and avoidance in marine invertebrates - their possible role in developing an artificial bait. J Cons Int Explor Mer 35:328-331

Hébert M, Miron G, Moriyasu M, Vienneau R, DeGrâce P (2001) Efficiency and ghost fishing of snow crab (Chionoecetes opilio) traps in the Gulf of St. Lawrence. Fish Res 52:143-153

High WL, Worlund DD (1979) Escape of king crab (Paralithodes camtschatica) from derelict pots. NOAA Tech Rep NMFS SSRF-734:1-11

Jennings S, Kaiser MJ (1998) The effects of fishing on marine ecosystems. Adv Mar Biol 34:201-352

Jury SH, Howell H, O'Grady DF, Watson WH III (2001) Lobster trap video: in situ video surveillance of the behaviour of Homarus americanus in and around traps. Mar Freshw Res 52:1125-1132

Kimker A (1994) Tanner crab survival in closed pots. Alsk Fish Res Bull 1:179-183

Kruse GH, Kimker A (1993) Degradable escape mechanisms for pot gear: a summary report to the Alaska Board of Fisheries. Regional Information Report RIR 5J93-01, Alaska Department of Fish and Game, Juneau, AK

Livingstone $M$ (2001) A study into the effectiveness of escape panels for Norway lobster, Nephrops norvegicus (L.), with application to the Torridon fishery. BSc dissertation, Scottish Agricultural College, Edinburgh

Matsuoka T, Nakashima T, Nagasawa N (2005) A review of ghost fishing: scientific approaches to evaluation and solutions. Fish Sci 71:691-702

Miller RJ (1990) Effectiveness of crab and lobster traps. Can J Fish Aquat Sci 47:1228-1251

Parrish FA, Kazama TK (1992) Evaluation of ghost fishing in the Hawaiian lobster fishery. Fish Bull (Wash DC) 90: $720-725$

Paul JM, Paul AJ, Kimker A (1994) Compensatory feeding capacity of two brachyuran crabs, Tanner and Dungeness, after starvation periods like those encountered in pots. Alsk Fish Res Bull 1:184-187

Pawson MG (2003) The catching capacity of lost static fishing gears: introduction. Fish Res 64:101-105

Editorial responsibility: Romuald Lipcius, Gloucester Point, Virginia, USA
Pecci KJ, Cooper RA, Newell CD, Clifford RA, Smolowitz RJ (1978) Ghost fishing of vented and unvented lobster, Homarus americanus, traps. Mar Fish Rev 40:9-43

Perry H, Larsen K, Richardson B, Floyd T (2003) Ecological effects of fishing: biological, physical, and sociological impacts of derelict and abandoned crab traps in Mississippi. J Shellfish Res 22:349

Queiros AM, Hiddink JG, Kaiser MJ, Hinz H (2006) Effects of chronic bottom trawling disturbance on benthic biomass, production and size spectra in different habitats. J Exp Mar Biol Ecol 335:91-103

Saldanha HJ, Sancho G, Santos MN, Puente E and others (2003) The use of biofouling for ageing lost nets: a case study. Fish Res 64:141-150

Stevens BG (1996) Crab bycatch in pot fisheries: causes and solutions. In: Solving bycatch: considerations for today and tomorrow. Proc of Solving Bycatch Workshop, Seattle, 25 to 27 September 1995. Report 96-03, University of Alaska Sea Grant College Program, Fairbanks, AK, p 151-158

Stevens BG, Vining I, Byersdorfer S, Donaldson W (2000) Ghost fishing by Tanner crab (Chionoecetes bairdi) pots off Kodiak, Alaska: pot density and catch per trap as determined from sidescan sonar and pot recovery data. Fish Bull (Wash DC) 98:389-399

Swarbrick J, Arkley K (2002) The evaluation of ghost fishing preventors for shellfish traps. DEFRA commission MF0724 under the Programme Impact of Fishing. Seafish Report SR549, Sea Fish Industry Authority, Hull

Tillin HM, Hiddink JG, Jennings S, Kaiser MJ (2006) Chronic bottom trawling alters the functional composition of benthic invertebrate communities on a sea-basin scale. Mar Ecol Prog Ser 318:31-45

Tuck ID, Hall SJ, Robertson MR, Armstrong E, Basford DJ (1998) Effects of physical trawling disturbance in a previously unfished sheltered Scottish sea loch. Mar Ecol Prog Ser 162:227-242

Wester Ross Biodiversity Group (2004) The Wester Ross Biodiversity Action Plan. Highland Biodiversity Project, Inverness

Zar JH (1999) Biostatistical analysis, 4th edn. Prentice Hall, Upper Saddle River, NJ

Zeigler F (2006) Environmental life cycle assessment of Norway lobster (Nephrops norvegicus) fished by creels, conventional and species-selective trawls along the Swedish coast. A data report. SIK Report 746, Swedish Institute for Food and Biotechnology, Göteborg

Submitted: July 9, 2007; Accepted: April 10, 2008

Proofs received from author(s): August 12, 2008 